\title{
Crisis Resource Management in Aviation and in Healthcare
}

\author{
https://doi.org/10.3991/ijac.v13i2.17035
}

\author{
Fernando Salvetti $(\bowtie)$
}

Centro Studi Logos, Turin, Italy - Logosnet, Lugano, Switzerland and Houston, TX, USA salvetti@logosnet.org

\section{Roxane Gardner}

Center for Medical Simulation, Boston, MA, USA

Brigham and Women's Hospital / Children's Hospital / Massachusetts General Hospital / Harvard Medical School, Boston, MA, USA

Rebecca Minehart

Center for Medical Simulation, Boston, MA, USA

Massachusetts General Hospital / Harvard Medical School, Boston, MA, USA

Cristiano Galli

Global Aerospace Logistics / Air Defense Institute of the Emirates Air Force, Abu Dhabi, UAE

\section{Barbara Bertagni}

Centro Studi Logos, Turin, Italy - Logosnet, Lugano, Switzerland and Houston, TX, USA

\begin{abstract}
Modern aviation crisis resource management focuses on specific skills and competencies areas: communication, situational awareness, decisionmaking, problem solving, teamwork and leadership. Effective teamwork during a crisis is also a core element of expert practice in healthcare, wherein professionals are challenged to recognize a situation that requires rapid intervention, communication, knowledge sharing, decision-making and management of unforeseen events - all the while also taking into consideration critical contextual factors such as a lack of time, scarcity of resources and tools, and a multitude of impactful factors. Simulation contributes enormously to enhancing teamwork during a crisis, as well as fostering situational awareness, contextual intelligence, and cognitive retention of essential steps and procedures to be performed during crisis. e-REAL $\AA$, which is a setting simulation based on mixed - or hybrid - reality, yields better results for enhancing teamwork compared with those reached within the other settings available today, such as CAVE-like environments and highly realistic simulation labs, virtual reality head-mounted displays, or computer-based e-learning environments.
\end{abstract}

Keywords-Aviation, Healthcare, Crisis Management, Teamwork, e-REAL Simulation 


\section{Crew Cockpit Resource Management in Aviation and Teamwork}

Since the late 1950s, Crew and Cockpit Resource Management has been a central topic for ensuring a safe and efficient conduct of flying missions - first in civil aviation, followed by military support and fighter crews. Crew resource management grew out of the 1977 Tenerife airport disaster where two Boeing 747 aircraft collided on the runway killing 583 people [1].

More recently, similar programs have been adopted by other high reliability team environments including aviation maintenance, air traffic control, the merchant navy, the nuclear power industry, the offshore oil industry, and healthcare specialties such as anesthesia, labor and delivery, telemedicine, etc. Our focus in this paper is on aviation and healthcare.

In the aviation industry, functions in the flight cockpit were strictly connected to hierarchical roles up until 1977. The role of Aircraft Commander was extremely important and authoritative. An Aircraft Commander was responsible for almost all decisions in non-standard situations and, most of all, during in-flight emergencies. This team dynamic left little space for assertiveness from other crew members and even less room for an active contribution to mission success from a collective action perspective.

Guided by a significant global effort from all national and international aviation authorities, Crew and Cockpit Resource Management training emerged after the recognition that the technical skills of piloting an aircraft were insufficient to ensure safety and best performance; accidents were occurring for reasons other than inadequate piloting skills. The practice has since grown dramatically: creating procedures, standards and training to enable high performance teamwork aimed at minimizing risk in such a complex environment like the aviation industry.

Modern aviation Crew and Cockpit Resource Management focuses on the following specific skills and competencies: communication, situational awareness, decisionmaking, problem solving, teamwork and flight leadership.

An important innovative approach was introduced to assign cockpit roles that positively influenced team dynamics; CM1 is the Pilot in Command and refers to the Captain, who always flies in the cockpit left seat; CM2 is the Co-Pilot role and sits in the right seat. Standing roles of CM1 and CM2 have been related to legal responsibilities on the ground and, in certain situations, in the air. These roles are always standing and the checklist duties refer specifically to these roles where necessary, and mainly in accordance with instrumentation ergonomics and legal responsibilities [2].

Once aligned on the runway and ready for take-off, new functional roles are established: PF and PM. PF stands for Pilot Flying and PM for Pilot Monitoring. These functional roles are not related to crew seniority- $\mathrm{CM} 2$ could be PF and vice versa. The important implication of these functional roles is that, even during emergency situations, functional roles do not change. PF and PM roles remain unchanged during the entire flight, allowing for a better workload distribution and increased situation awareness inside the cockpit. 
In standard flight situations, PF is responsible for maintaining aircraft control and ensuring the aircraft maintains correct flight path parameters (attitude, altitude, speed, direction and configuration). PM is responsible for monitoring the PF and also handling checklist procedures and radio communications.

During emergency or abnormal situations, PF takes control of radio communications allowing the PM to concentrate on problem analysis and emergency checklist actions. Another important element has been the introduction of the AP (Auto Pilot) as an integral part of crew duties. When flying in autopilot, task sharing inside the cockpit leaves more space for human interaction. Without autopilot, PF is solely devoted to aircraft control leaving all the remaining tasks to PM.

Any emergency or abnormal situation inside the cockpit is handled by following 3 steps (Figure 1): maintain aircraft control, analyze the situations and take the proper actions, and land as soon as conditions permit.

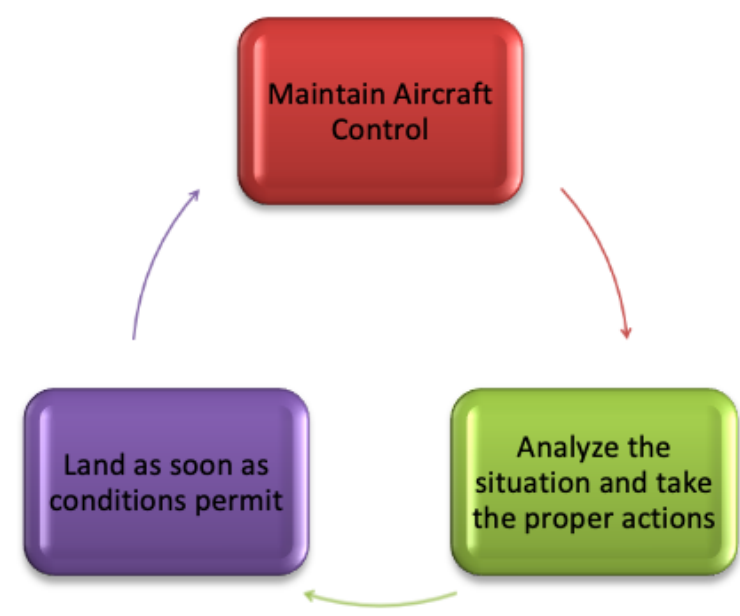

Fig. 1. Steps to follow in abnormal situations

An important part of maintaining aircraft control relates to specific and limited critical checklist items (engine shutdown, oxygen masks, aircraft configuration, altitude and directional control, etc.) called "memory items." Specific studies on the effects of stress response on working memory have proven the cruciality of executing critical actions without needing a double check from both crewmembers. For this reason, memory items have been limited as much as possible and are part of constant and continuous training and verification among crewmembers [3].

All non-memory item actions are instead applied by the PM after a positive "confirm" call by the PF.

Follow-on analysis and action plans to recover the aircraft to the safest available landing site is taken with a collective approach, making sure all crewmembers are aligned on the decision. Assertiveness from every crewmember is strongly encouraged and active listening is part of the core values of modern flying crews. 
In the latest development of aviation Crew and Cockpit Resource Management, even cabin crews (flight attendants) are actively involved in abnormal or emergency management. Since the 1980s, these programs focus on "non-technical" skills that are critical for enhanced operational performance, such as leadership, situation awareness, decision-making, teamwork and communication.

Our hypothesis-which is currently under test and review-for enhancing teamwork, which is an essential component of the "non-technical" skills, is that simulation within a setting based on mixed, or hybrid, reality called e-REAL $®$ allows for better results compared with those reached within the other settings available today, such as CAVE-like environments and highly realistic simulation labs, virtual reality head-mounted displays, or computer based e-learning environments.

A number of tests are expected to be performed within the e-REAL immersive labs at the Polytechnic School of Milan and at the University Marconi in Rome. However, due to the Covid-19 crisis, all the tests had to be postponed.

Tests will be focused on teamwork, crisis management and decision-making. Starting in September 2020, the tests performed will be designed as an escape game within an e-REAL setting - in which a team of players cooperatively discovers clues, solves puzzles, and accomplishes tasks in order to progress and accomplish a specific goal in a limited amount of time (Figures 2 and 3).

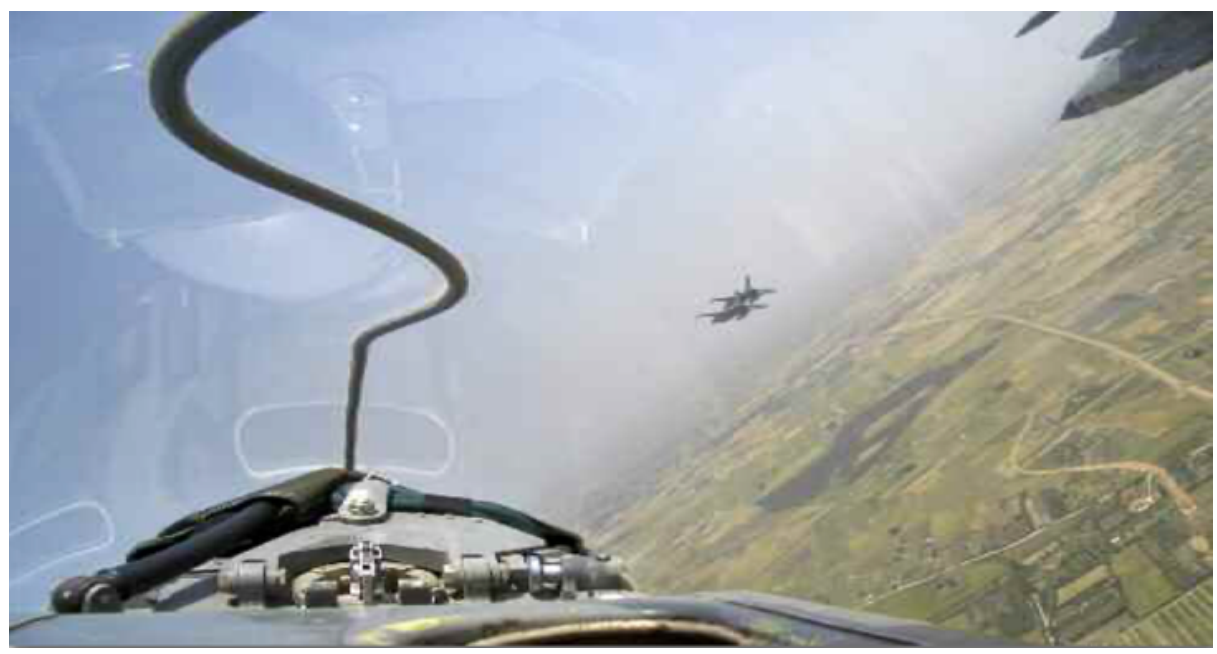

Fig. 2. Advanced simulation tests expected to be performed within the e-REAL $®$ labs at the Polytechnic School of Milan and at the University Marconi in Rome (Italy): flight scenario $\odot$ by EDME \& Logosnet 


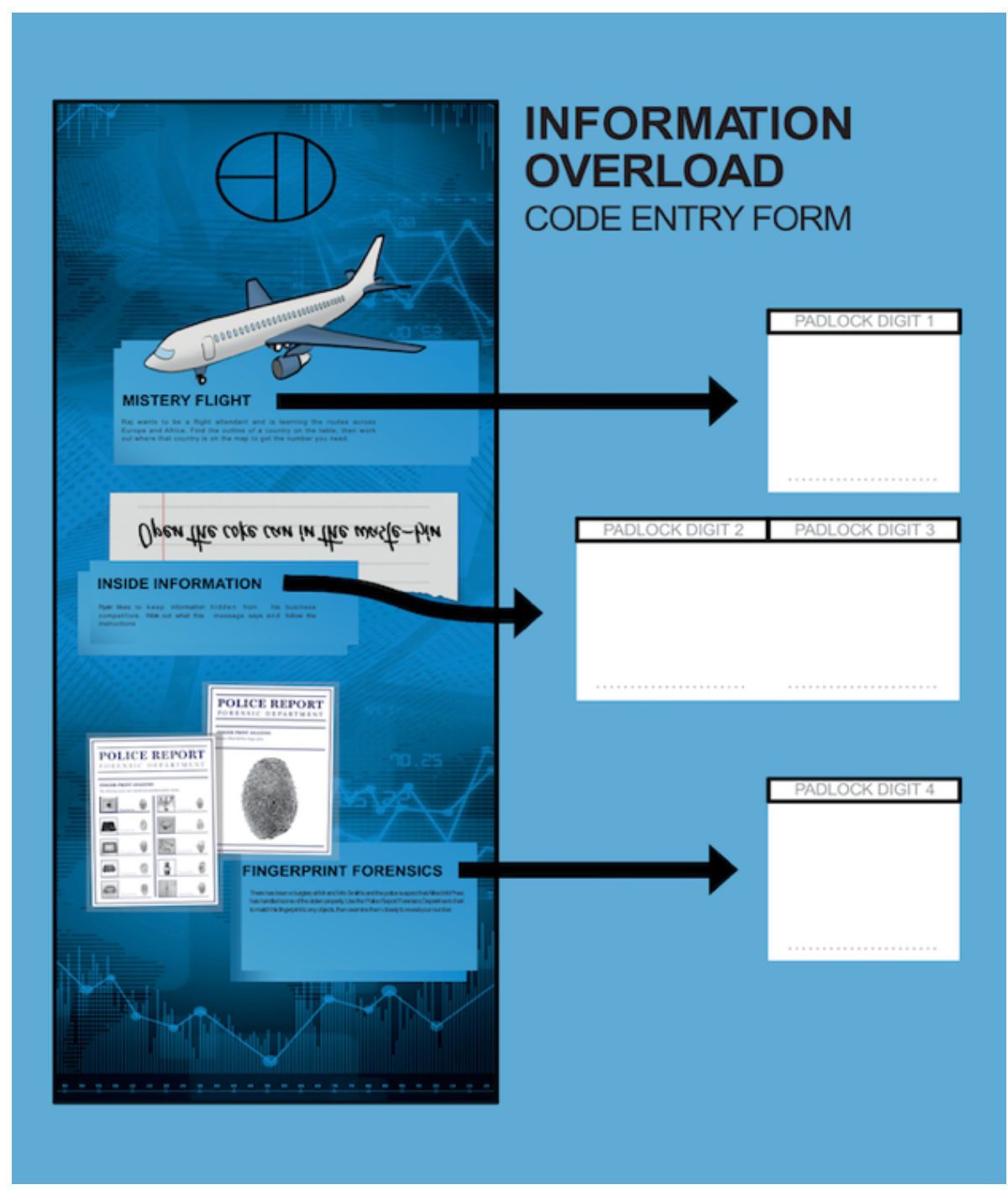

Fig. 3. Advanced simulation test expected to be performed within the e-REAL ${ }^{\circledR}$ labs at the Polytechnic School of Milan and at University Marconi in Rome (Italy): multitasking scenario $\subset$ by Nolec Training \& Logosnet

\section{Teamwork and Crisis Resource Management in Healthcare}

Effective teamwork during a crisis is also a core element of expert practice in healthcare, wherein professionals are challenged to recognize a situation that requires rapid intervention, communication, knowledge-sharing, decision-making and management of unforeseen events - all the while also taking into consideration critical 
contextual factors such as a lack of time, scarcity of resources and tools, and a multitude of impactful factors.

After several decades of dedicated simulation education for anesthesiologists and labor and delivery teams, teamwork experts at the Center for Medical Simulation (CMS) in Boston, Massachusetts, have found that these teams still struggle to routinely organize themselves in crises during simulation courses, let alone in the clinical environment [4][5][6][7].

Stories from course participants of all professions indicate that there still exists a real challenge to simultaneously focus on the clinical picture and apply organizational principles to the team, and more often than not, the organization within the team is under-prioritized. Part of this may be due to the intense cognitive load experienced by those who are managing a stressful clinical crisis.

"Name-Claim-Aim," a crisis management organizational approach that uses a mnemonic device, was developed at CMS and is being used in order to facilitate crisis management and decision-making (Figure 4).

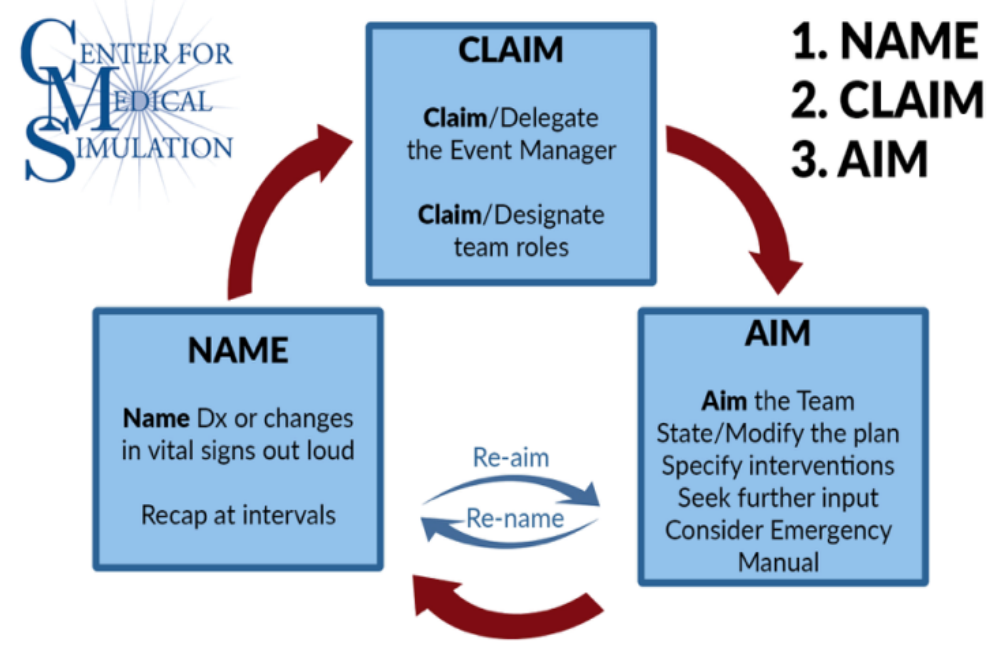

Fig. 4. Name-Claim-Aim $₫$ mnemonic by CMS

Knowledge and technical skills are essential components of the decision-making process and actions performed during crises, but they are not sufficient to manage the entire situation, which includes the environment, the equipment and the patient care team with its organizational behavior.

Therefore, an "Event Manager Checklist" was created to facilitate effective role designation. Participants have been given this cognitive aid, designed as an ID badgesized card, to easily access during their simulation course (Figure 5). 


\begin{tabular}{l}
\multicolumn{1}{c|}{ BASIC Roles } \\
1. Event Manager \\
2. Circulation - CPR \\
3. Airway \\
4. Drugs \\
5. Recorder / Timer \\
6. Resource Person \\
$\quad$ Additional Roles \\
IVs, Fluids, Labs \\
Hx\& Chart Review \\
Liaison w/ Extemal Services \\
\& Phone \\
Securty \& Crowd Control \\
Technical Equipment \\
Monitor Watcher \\
Emergency Manual Reader
\end{tabular}

Fig. 5. Event Manager Checklist $C$ by $\mathrm{CMS}$

The role of "Event Manager," rather than "Team Leader," is expressly promoted at CMS to facilitate distributed leadership in crises. This distinction has proven to be effective in teams of expert practitioners because it deliberately seeks to flatten hierarchies that may otherwise inhibit speaking-up behavior from team members. This practice, in turn, may successfully counteract failures of perception [8].

The Event Manager coordinates the communication and the team's efforts, overseeing the organization and application of CRM principles, in addition to actively soliciting input and decision-making regarding medical care, if necessary. Moreover, the Event Manager acts to facilitate role designation, as well as orchestrate and coordinate team function.

Cognitive aids like these are proven to be very effective: a few years ago, the "NameClaim-Aim" and "Event Manager Checklist" were adopted by the Massachusetts General Hospital (MGH) in Boston, Massachusetts, for inclusion in the latest version of their Emergency Manuals (Figure 6).

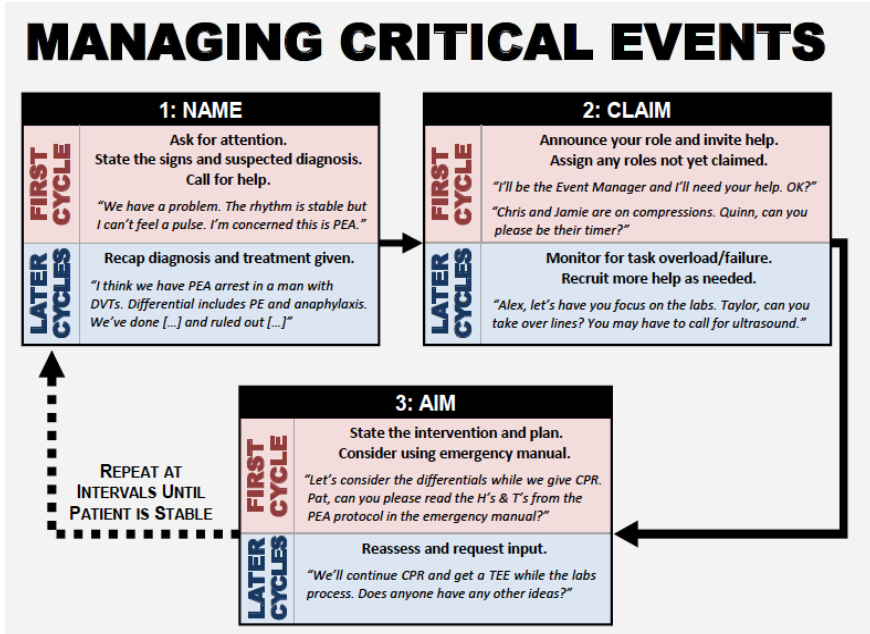

Fig. 6. Name-Claim-Aim $\subset$ mnemonic and Event Manager $\odot$ checklist by $\mathrm{CMS}$ as redesigned into the MGH Emergency Manual 


\section{Teamwork and Crisis Resource Management within a Mixed Reality Setting (e-REAL)}

Simulation contributes enormously to enhancing teamwork during a crisis, as well as fostering situational awareness, contextual intelligence, and cognitive retention of essential steps and procedures to be performed during crises.

To enhance teamwork, a simulation within a setting based on mixed —or hybridreality called e-REAL $\AA$ allows for better results compared with those reached within the other settings available today such as: high fidelity flight simulators, highly realistic healthcare simulation labs, virtual reality head-mounted displays, computer-based elearning environments.

e-REAL is shorthand for 'enhanced reality,' which is the merging of real and virtual worlds: a mixed reality (MR) environment for hybrid simulation where physical and digital objects (VR) co-exist and are available for tactile and vocal interaction, in a learning setting that is both physical and online (figure 7)[9][10][11].

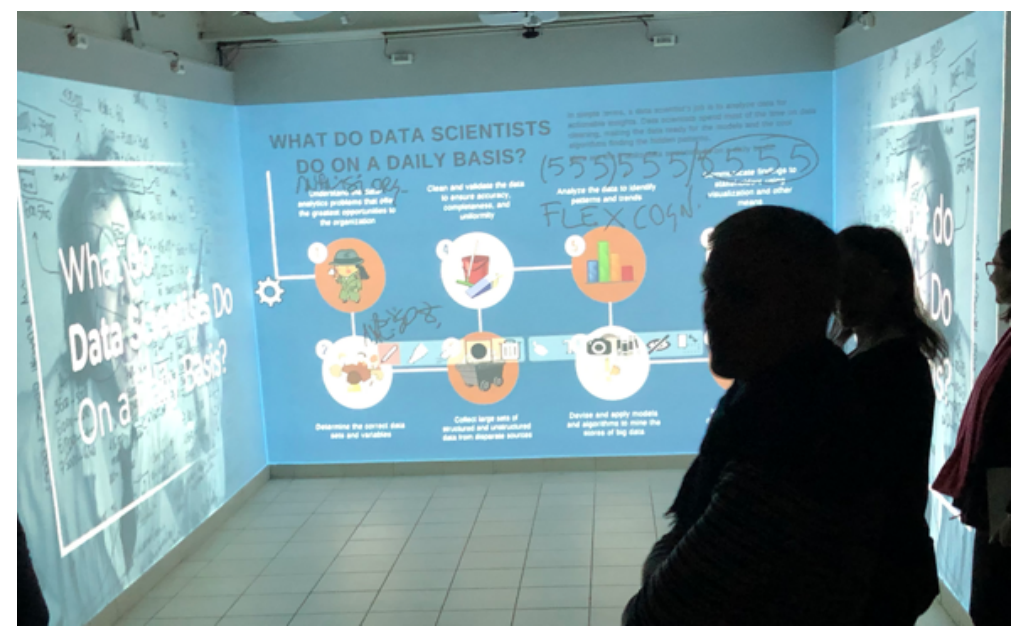

Fig. 7. e-REAL ${ }^{\circledR}$ physical setting, usually complemented by an online learning environment allowing for a blended program

e-REAL enables a multilayer vision; the many levels of the situation are made available simultaneously by overlaying multisource info-words, numbers, images, etc. - similar to an augmented reality display, but without needing to wear special glasses. Through different contextual factors, cognitive maps and dynamic cognitive aids, e-REAL improves the learners' cognitive retention by making the relationships between topics visual, which yields better results compared with those from the other systems.

e-REAL offers a unique user experience: a combination of visual communication and direct interaction with the content-by gesture or spoken commands - that immerses people in an entirely interactive ecosystem. Figures 8-9 provide a visual explanation of the main features of the system. 


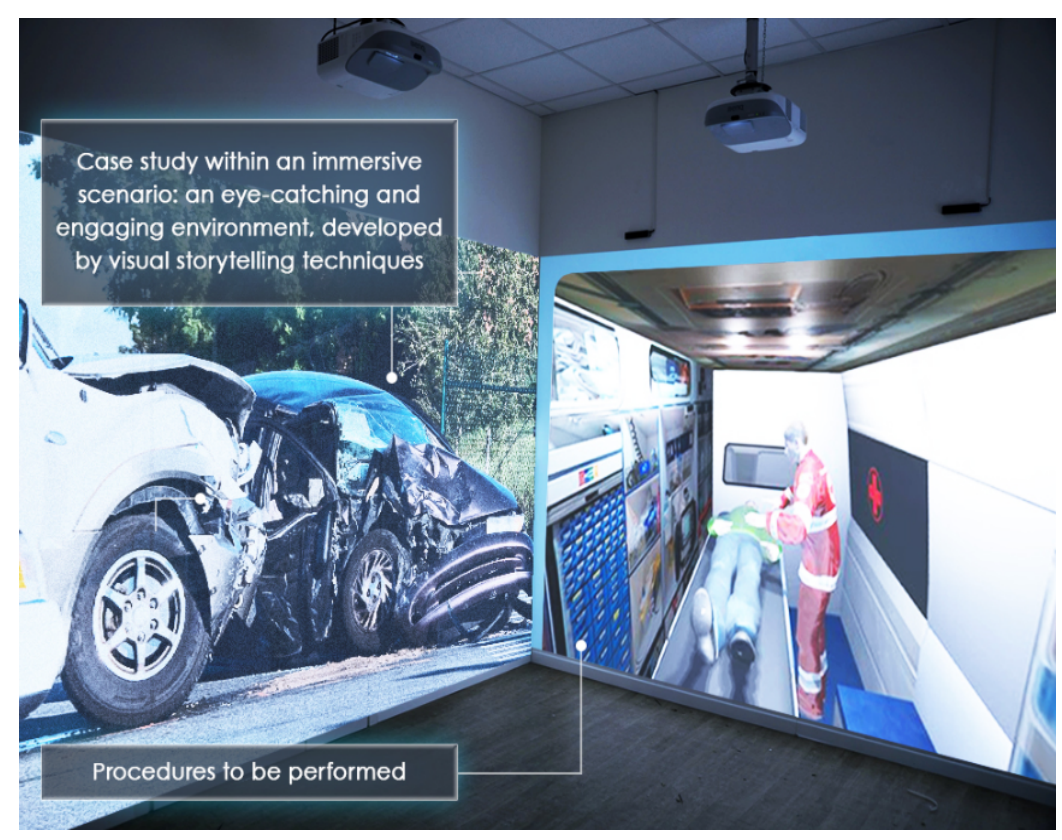

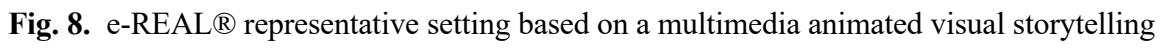
made interactive by touch sensors tracking fingers and by vocal commands

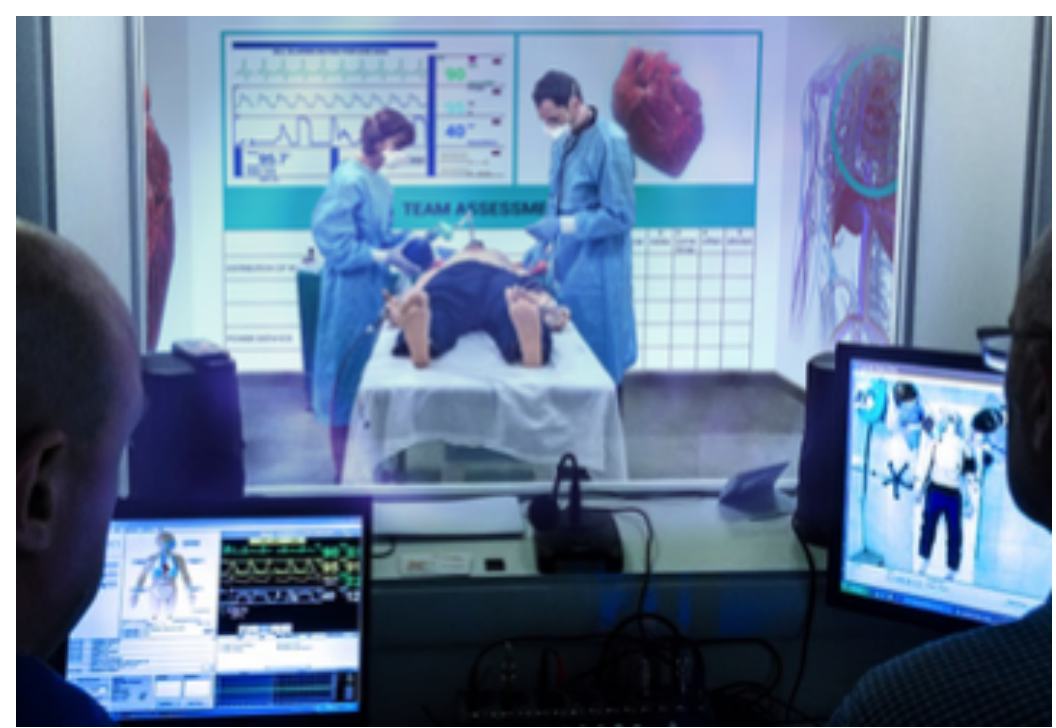

Fig. 9. e-REAL ${ }^{\circledR}$ setting with medical imagery on the side walls, a $3 D$ beating heart on the top-right corner of the main screen which can be rotated 360 degrees and can be overlaid with annotations and visualization of medical exams on the top-left corner of the same central wall 
Visual storytelling techniques are part of the e-REAL simulation scene and serve to represent a realistic context where learners are proactively involved in analyzing scenarios and events, facing technical issues, and solving problems. The most effective learning occurs when being immersed in a context; realistic experience is lived and perceived as a focal point and as a crossroad [12].

Effective visualization is the key to help untangle complexity. The visualization of information enables learners to gain insight and understanding quickly and efficiently.

Examples of such visual formats include sketches, diagrams, images, objects, interactive visualizations, information visualization applications, and imaginary visualizations, such as stories.

Visualizations within e-REAL show relationships between topics, activate involvement, generate questions that learners didn't think of before, and facilitate memory retention. Visualizations act as concept maps to help organize and represent knowledge on a subject in an effective way.

Within interactive scenarios that present a wealth of information, learners are challenged both cognitively and behaviorally in a fully-immersive and multitasking learning environment. The many levels of the situation are made available simultaneously, by overlaying multisource information - words, numbers, images, etc. - within an environment designed using augmented reality.

e-REAL submerges learners in an immersive reality where the challenge at hand is created by sophisticated, interactive computer animation. Importantly, the system includes live and real time interaction with peers, instructors, tutors, facilitators and mentors. Thus, it adds a very important social component that enhances learning outputs, skills, cognitive and metacognitive processes. The process of learning by doing within an immersive setting, based on knowledge visualization using interactive surfaces, leaves the learners with a memorable experience and an effective know-how gained from the simulation field.

The e-REAL setting is a further evolution of a flipped learning approach. The flipped learning approach is based mainly on video-lectures. However, critics have argued that this model has some drawbacks for both learners and trainers, particularly that video lectures may facilitate a passive and uncritical attitude towards learning, similar to that of didactic face-to-face lectures, which does not encourage dialogue and questioning.

e-REAL's vision and model is based on a constructivist approach. Constructivism is not a specific pedagogy, but rather a psychological paradigm that suggests that humans construct knowledge and meaning from their experiences. From our constructivist point of view, knowledge is mainly the product of personal and interpersonal exchange. Knowledge is constructed within the context of a person's actions, so it is "situated." It develops in dialogic and interpersonal terms, through forms of collaboration and social negotiation. Significant knowledge - and know-how - is the result of the link between abstraction and concrete behaviors.

Knowledge and action can be considered as one: facts, information, descriptions, skills, know-how and competence-acquired through experience, education and training. Knowledge is a multifaceted asset: implicit, explicit, informal, systematic, practical, theoretical, theory-laden, partial, situated, scientific, based on experience and experiments, personal, shared, repeatable, adaptable, compliant with socio-professional 
and epistemic principles, observable, metaphorical, linguistically mediated. Knowledge is a fluid notion and a dynamic process, involving complex cognitive and emotional elements for both its acquisition and use: perception, communication, association and reasoning. In the end, knowledge is derived from minds at work. Knowledge is socially constructed, so learning is a process of social action and engagement involving ways of thinking, doing and communicating.

From our perspective, e-REAL is one of the most promising methods in today's panorama of immersive and interactive learning methodologies, because it encourages learners to learn by doing and allows them to cross conceptual and theoretical boundaries with the help of simulation or game-based tools.

The e-REAL experiences are designed to have the learners working on tasks that simulate an aspect of expert reasoning and problem-solving, while receiving timely and specific feedback from both the trainers and fellow learners. These elements of deliberate practice and feedback are general requirements for developing expertise at all levels and disciplines. During an e-REAL session, a number of skills and competencies are challenged: on one side technical knowledge and know-how are tested and, on the other side, behavioral, cognitive and metacognitive skills, such as leadership and followership, team-work facilitation, team spirit and effectiveness, knowledge circulation, effective communication, relationships and power distance, fixation error management and metacognitive flexibility. Feedback is provided throughout sessions with a focus on key performance indicators.

The e-REAL system allows trainers to provide feedback about key aspects of performance, using different tracking options. The system also allows multi-source feedback during the simulation-based session, combining self-assessment with feedback from the other participants and the trainers. This activity improves the learners' awareness of their own competencies.

The main goal within e-REAL is allowing a multi-perspective mindset during a simulation session. Visualizing the "invisible" by overlaying information that focuses on both technical and behavioral aspects of a performance, and merges the virtual and the real, creates a multilayer and therefore augmented, multi-perspective, and systemic simulation that contributes to better learning outputs.

\section{$4 \quad$ Early Findings}

Regarding Crew and Cockpit Resource Management in aviation, tests about teamwork during a crisis will be performed beginning in September 2020, so currently we do not have evidence.

For Crisis Resource Management and teamwork in healthcare, we performed a number of experiments within the e-REAL Virtual Room at the Environmental Design and Multisensory Experience Lab from the Polytechnic School of Milan (Italy). This was the first research phase, that will be followed by a second one to be performed at CMS in Boston from October 2020.

Tests were designed to compare the learning outcomes of the same Teamwork and Crisis Resource Management Course, but delivered with three different methodologies: 
- Classroom-based lesson

- Virtual reality head-mounted displays

- e-REAL immersive setting.

The research hypothesis is that, for enhancing teamwork during crisis resource management situations, simulation within an e-REAL setting allows for better results compared with those reached within the other two learning settings.

For this first phase of the research, we evaluated a sample of 62 participants that were enrolled in a 1-day training program called "Teamwork and Crisis Resource Management." Participants and trainings were divided into 6 different cohorts that ran from October 21, 2019 to March 6, 2020.

Each cohort was composed of undergraduate medical students, graduates from several healthcare programs, student nurses and professional first responders - in order to reproduce an interprofessional team.

The focus of the experiments was on:

- Speed and ease of learning

- Engagement and enjoyment during learning

- Effective understanding

- Cognitive retention

- Confidence and readiness in applying the learning outputs in crisis situations.

The training started with an introduction of the main concepts in a traditional classroom-based setting. After one hour, the students were divided into three different groups and expected to learn the checklist for managing critical events (Name-ClaimAim). The first group was involved in a traditional classroom-based lesson, the second group was provided with virtual reality head-mounted displays to use in a self-learning mode, and the third group was involved within the e-REAL setting.

The training program was the same, while the activities were different because learners were divided into three groups - two of them, i.e., those not experiencing the e-REAL setting, working as control groups.

In the first group (control), participants interacted with a trainer that was presenting the topic through a presentation based on slides and verbal reconstruction of different scenarios.

In the second group (control), each participant was wearing VR glasses and went through the topics by exploring real crisis situations reproduced in the virtual scenarios.

In the e-REAL setting, participants were all together in the immersive room, working as a team within different scenarios projected on three walls. They were allowed to go through the checklist overlayed on the same scenarios, and one by one practiced a suggested script designed to effectively perform as a team and organize the team response step by step. 


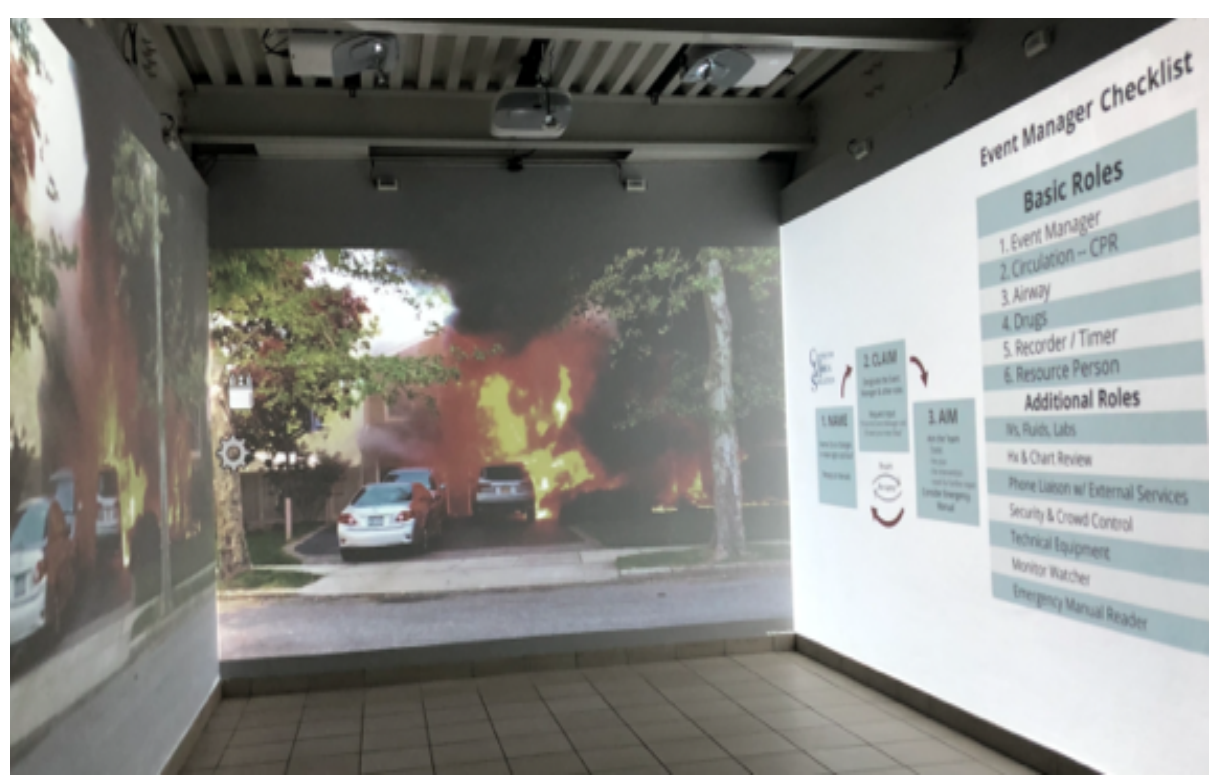

Fig. 10. e-REAL $\AA$ experimental setting

After this experience, all participants came back together in the main classroom where they went ahead with the program, starting by playing a simulation during which they were expected to be able to perform as a team following the same checklist learned during the previous stage.

We collected data from observation during all the activities and by individual interviews at the end of the training program.

Early findings show that learners that entered the e-REAL experience were more self-confident in the checklist learned in the simulation and ready to apply it when they had to play it out once back in the main classroom. Also, the quality of the communication in the team who experienced the e-REAL system was more clear, effective, and precise.

Sixty-four percent of the students in the two control groups reported that practicing the checklist for the first time during the simulation was emotionally overwhelming and very difficult because most of their attention was devoted to facing the case at hand. Additionally, 38\% of the students in the second group reported a sense of sickness from the VR head-mounted displays.

Learners who experienced the e-REAL simulation reported an average performance gain of $43 \%$ in terms of increased speed and ease of learning, when compared to a traditional face-to-face classroom lesson or a self-learning VR program. Eighty-eight percent of e-REAL learners also reported increased engagement and enjoyment.

Overall, the students that experienced the e-REAL system were able to perform the checklist with a good degree of autonomy (5 out of 7 on a Likert scale), while the students from the two control groups needed active input from the trainer to effectively perform the same checklist ( 2 out of 7 on a Likert scale for those from the VR glasses control group, 3 out of 7 for those from the other control group). 
In our opinion, the e-REAL setting created simpler and more immediate learning of the checklist, because of the presence of the team and the ability to practice and debrief altogether within an immersive environment surrounding them (mixed reality).

\section{$5 \quad$ References}

[1] Helmreich, R.L., Merritt, A.C. and Wilhelm, J.A., 1999. The evolution of crew resource management training in commercial aviation. The International Journal of Aviation Psychology, 9(1), pp.19-32. https://doi.org/10.4324/9781315092898-15

[2] Helmreich, R.L. and Foushee, H.C., 1993. Why crew resource management? Empirical and theoretical bases of human factors training in aviation. Academic Press. https://doi.org/ 10.1016/b978-0-12-374946-8.10001-9

[3] Maltby C. 2013. Research Project EASA. 2013.01 Checklist Memory Items. European Aviation Safety Agency.

[4] Minehart R., Rudolph J., Nadelberg R., Clinton E., Gardner R., 2019. Name/Claim/Aim for Obstetric Crises: A New Paradigm in Crisis Resource Management, Poster Communication: Phoenix, AZ: SOAP 51th Annual Meeting.

[5] Minehart R., Pian-Smith M., Walzer T., Gardner R., Rudolph J., Simon R., Raemer D., 2012. Speaking Across the Drapes. Communication Strategies of anesthesiologists and Obstetricians During a Simulated Maternal Crisis. In: Simulation in Healthcare, 7: 166-170. https://doi.org/10.1097/sih.0b013e31824e73fb

[6] Salvetti F., Gardner R., Minehart R., Bertagni B., 2019. Teamwork and Crisis Resource Management for Labor and Delivery Clinicians: Interactive Visualization to Enhance Teamwork, Situational Awareness, Contextual Intelligence and Cognitive Retention in Medical Simulation, Research Paper. New York, NY: ICELW 2019 at Columbia University.

[7] Salvetti F., Gardner R., Minehart R., Bertagni B., 2020. Enhanced Reality for Healthcare Simulation, in Brooks A.L., Branham S., Kapralos B., Nakajima A., Tyerman J., Jain L. (Eds.). Recent Advances in Technologies for Inclusive Well-Being: Virtual Patients, Gamification and Simulation. Springer-Verlag, Intelligent Systems Reference Library, Germany (to be published). https://doi.org/10.1007/978-3-319-49879-9

[8] Raemer D.B., Kolbe M., Minehart R.D., Rudolph J.W., Pian-Smith M.C. (2016). Improving Anesthesiologists' Ability to Speak Up in the Operating Room: A Randomized Controlled Experiment of a Simulation-Based Intervention and a Qualitative Analysis of Hurdles and Enablers. Acad Med. Apr; 91(4):530-9. https://doi.org/10.1097/acm.00000000000 $\underline{01033}$

[9] Salvetti F., Bertagni B.(eds.), 2018. Learning 4.0. Advanced Simulation, Immersive Experiences and Artificial Intelligence, Flipped Classrooms, Mentoring and Coaching. Milan: Franco Angeli.

[10] Salvetti F., Gardner R., Minehart R., Bertagni B., 2019. Teamwork and Crisis Resource Management for Labor and Delivery Clinicians: Interactive Visualization to Enhance Teamwork, Situational Awareness, Contextual Intelligence and Cognitive Retention in Medical Simulation, Research Paper. New York, NY: ICELW 2019 at Columbia University.

[11] Salvetti F., Gardner R., Minehart R., Bertagni B., 2020. Enhanced Reality for Healthcare Simulation, in Brooks A.L., Branham S., Kapralos B., Nakajima A., Tyerman J., Jain L. (Eds.). Recent Advances in Technologies for Inclusive Well-Being: Virtual Patients, Gamification and Simulation. Springer-Verlag, Intelligent Systems Reference Library, Germany (to be published). https://doi.org/10.1007/978-3-319-49879-9 
[12] Guralnick D. (2018). Re-Envisioning online learning. In: Salvetti F., Bertagni B. (eds.). Learning 4.0. Advanced Simulation, Immersive Experiences and Artificial Intelligence, Flipped Classrooms, Mentoring and Coaching. Milan: Franco Angeli.

\section{Authors}

Fernando Salvetti (J.D., P.P.E., M.Phil., Ph.D.), Founder of Centro Studi Logos in Turin and Logosnet in Lugano, Berlin and Houston, is an epistemologist, an anthropologist and a lawyer who co-designed e-REAL, the enhanced reality lab where virtual and real worlds are merging within an advanced simulation environment. He is committed to exploring virtual and augmented reality, cognitive aids by artificial intelligence, visual thinking, interactive and immersive learning, emerging scenarios and trends, and cross-cultural intelligence (salvetti@logosnet.org).

Roxane Gardner (M.D., M.H.P.E., M.P.H., Ph.D.), Senior Director for Clinical Programs and Director of the Visiting Scholars and Fellowship Program at the Center for Medical Simulation in Boston (CMS), has been a principle faculty member of CMS since 2002 and Co-Director of its Labor and Delivery Teamwork and Crisis Management program since its inception in 2003. In addition to her roles at CMS, Dr. Gardner is an Assistant Professor of Obstetrics, Gynecology and Reproductive Biology at the Harvard Medical School and holds appointments in Boston at Brigham and Women's Hospital, Boston Children's Hospital, and Massachusetts General Hospital (rgardner1@bwh.harvard.edu).

Rebecca D. Minehart (M.D., M.S.H.P.Ed.), Director for Anesthesia Clinical Courses at the Center for Medical Simulation in Boston (CMS), is an obstetric anesthesiologist at Massachusetts General Hospital (MGH), an Assistant Professor of Anesthesia at Harvard Medical School, and the Program Director for the MGH Obstetric Anesthesia Fellowship Program. She is an ardent education and patient safety advocate who has been involved in international efforts to both research and promote best teamwork and communication practices, especially involving speaking up and giving feedback. She is a recognized expert in educational techniques utilizing simulation and is a core teaching faculty member at both CMS and the MGH Learning Laboratory, where she serves as the Operating Room Simulation Officer (rminehart@mgh.harvard.edu).

Cristiano Galli (B.Sc., MSc Aviation, M.IA), is Professor on Command, Leadership and Management at the Emirates Air War College and at Global Aerospace Logistics in Abu Dhabi (UAE). Retired General of the Italian Air Force with 20+ years of operational experience in the aviation fighter combat business, he lead the Italian Air Force Center of Excellence for Leadership and Managerial Studies by the Italian Air Force War College in Florence. He was also the Commander of the Multi Crew Training Center of the Italian Air Force in Pratica di Mare (Italy) (cristiano.galli@nolec.training).

Barbara Bertagni (B.Sc., B.A., M.A., M.Phil., Ph.D., Clin.Psy.D), Founder of Centro Studi Logos in Turin and Logosnet in Lugano, Berlin and Houston, as well as e-REAL co-designer, is a clinical psychologist, an anthropologist and a practical philosopher particularly involved with personal and professional development, 
coaching and mentoring, immersive learning and advanced simulation. She is interested in design and foster learning solutions, involving both cognition and emotion, to help people develop competencies that enhance individual and organizational performance. She works as a sparring partner, advising people and organizations across the globe (bertagni@logosnet.org).

Article submitted 2020-07-14. Resubmitted 2020-08-10. Final acceptance 2020-08-11. Final version published as submitted by the authors. 